\title{
A New Small Drifter for Shallow Water Basins: Application to the Study of Surface Currents in the Muggia Bay (Italy)
}

\author{
Carmelo Nasello ${ }^{1}$ and Vincenzo Armenio ${ }^{2}$ \\ ${ }^{1}$ Dipartimento di Ingegneria Civile, Ambientale, Aerospaziale, dei Materiali, Università di Palermo, Viale delle Scienze, \\ 90128 Palermo, Italy \\ ${ }^{2}$ Dipartimento di Ingegneria e Architettura, Università di Trieste, Piazzale Europa 1, 34127 Trieste, Italy \\ Correspondence should be addressed to Carmelo Nasello; carmelo.nasello@unipa.it
}

Received 1 October 2015; Accepted 14 December 2015

Academic Editor: Jose C. Nieto-Borge

Copyright ( 92016 C. Nasello and V. Armenio. This is an open access article distributed under the Creative Commons Attribution License, which permits unrestricted use, distribution, and reproduction in any medium, provided the original work is properly cited.

\begin{abstract}
A new small drifter prototype for measuring current immediately below the free surface in a water basin is proposed in this paper. The drifter dimensions make it useful for shallow water applications. The drifter transmits its GPS location via GSM phone network. The drifter was used to study the trajectory of the surface current in the Muggia bay, the latter containing the industrial harbor of the city of Trieste (Italy). The analysis has been carried out under a wide variety of wind conditions. As regards the behavior of the drifter, the analysis has shown that it is well suited to detect the water current since its motion is marginally affected by the wind. The study has allowed detecting the main features of the surface circulation within the Muggia bay under different meteorological conditions. Also, the study has shown that the trajectory of the surface current within the bay is weakly affected by the Coriolis force.
\end{abstract}

\section{Introduction and Drifter Prototype Description}

The deployed drifters used to measure the surface current at sea are essentially of two types: drogued and undrogued [1]. The Surface Velocity Program (SVP) and the Coastal Ocean Dynamics Experiment (CODE) drifters are examples of drogued and undrogued drifters, respectively. The SVP has a subsurface holey-sock drogue centered at $15 \mathrm{~m}$ nominal depth $[2,3]$. The CODE measures coastal currents in the first meter below the free surface $[4,5]$.

The position of a drifter can be inferred from the Dopplerbased Argos tracking, or from a satellite GPS system [6]. The transmission of data uses terrestrial cellular phone networks (for coastal operations) or satellite global phone systems.

A former low cost (drogued) drifter, with GPS connection, but without data-transmission capability, has been employed to measure the mean subsurface currents between 2.5 and $8.5 \mathrm{~m}$ by Johnson et al. [7]. The instrument casing had a submerged area of $40 \mathrm{~cm}^{2}$, and an emerged portion of $48 \mathrm{~cm}^{2}$. Later on, Kõuts et al. [8] developed a low cost drifter,
GPS equipped and with GPRS communication, having a diameter of $0.11 \mathrm{~m}$ and a length of $1 \mathrm{~m}$. These buoys had a percentage of fault GPS positioning up to $20 \%$ in presence of waves, or less than $10 \%$ in calm water. A third low cost drifter had a submerged depth of $0.40 \mathrm{~m}$; the GPS (WAAS corrected) antenna emerged for $0.70 \mathrm{~m}$; the buoy did not have a datatransmission system [9].

Due to their dimensions, the above-mentioned systems cannot be employed in lagoons with water depth smaller than 1 meter. Since it is often necessary to measure the water current immediately below the water surface, a novel small drifter prototype was developed and its own features are presented in the present paper. It is suited for coastal basins, lakes, shallow lagoons, and river reaches, in particular close to obstacles where the main stream is deviated due to the occurrence of downstream separated regions. Due to its own inertia, the drifter is not able to adapt its trajectory to the turbulent fluctuations of the surface current and it measures the mean current in the first $0.20 \mathrm{~m}$ below the free surface. Accurate measurements of the water velocity near the free surface are gathered by means of this instrumentation and 


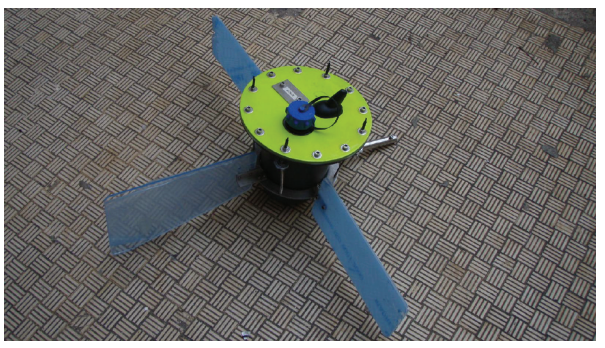

(a)

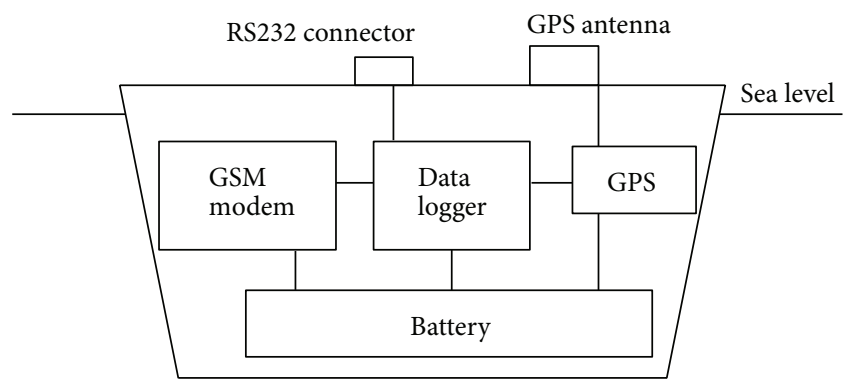

(b)

FIgURE 1: (a) Picture of the drifter equipped with the three wings; (b) schematic diagram of drifter.

used to detect trajectories of tracers transported at the free surface level.

The prototype drifters have a troncoconical shape, with a maximum diameter (at the top) of $0.30 \mathrm{~m}$ and height of $0.21 \mathrm{~m}$ (Figure 1(a)). Each drifter is equipped with three plastic wings to keep the trajectory stable during the motion and to avoid rotation around its own vertical axis. Two wings are rectangular $(0.30 \times 0.12 \mathrm{~m})$ and they increase the section of the drifter perpendicular to the current. The width of this section is $0.80 \mathrm{~m}$, bigger than twice the drifter diameter. The presence of the wings makes the drifter velocity very close to the local mean current velocity. The third wing has a trapezoidal shape since it operates as a helm. Overall, the depth of the system is of $0.20 \mathrm{~m}$. The buoy is not completely submerged; for GPS and GSM communication purposes, the top of the buoy emerges over the surface by $0.010 \mathrm{~m}$, the GPS antenna by $0.020 \mathrm{~m}$, and the connector RS232 by $0.015 \mathrm{~m}$. The part exposed to the wind is very small making its effect negligible in comparison to the mean current acting over the submerged part of the buoy. Inside, the drifter is equipped with a GPS satellite system, a GSM modem, a recording memory, and a battery (Figure 1(b)). Each trajectory is remotely sampled every 2 min by the GPS system and transmitted via GSM to the operator. GPS positions are corrected by means of the WAAS system, so that the overall error is smaller than $2 \div 3$ meters.

\section{Field Campaigns}

The drifters were used to sample the trajectory of the surface current in the Muggia bay under different meteorological conditions. The Muggia bay is inside the harbor area of the city of Trieste, Italy. The bay develops along the east-west axis for about $4 \mathrm{~km}$ and communicates with the Gulf of Trieste through the western section, about $3 \mathrm{~km}$ wide; there, the bay is delimited by three breakwaters that substantially affect water circulation. The bathymetry displays a shallow water basin, with a maximum depth of approximately $20 \mathrm{~m}$ in the western region close to the breakwaters, while in the eastern portion the depth decreases to about 5-10 m. The Northern side of the coast is characterized, from west to east, by docks of the harbor area of Trieste and by two wharfs belonging to an international oil terminal.
The drifters were released in the proximity of the wharfs close to the ships moored over there, and left in the water for a time interval of about $15 \mathrm{~h}$. Some drifters landed either at the shore or at the floating oil barriers below the wharfs. In both cases, they were recovered by the operators.

The drifters were launched during different field campaigns; in this paper we focus on the late-summer one, carried out over 5 days in September 2011 [10].

The wind velocity and direction were measured every second at a meteorological station, located $28 \mathrm{~m}$ a.s.l. on the western wharf of the oil terminal. The Muggia bay is characterized by a diurnal (270-330 from Northwest) and nocturnal $\left(90^{\circ}-150^{\circ}\right.$ from Southeast) breeze regime often interrupted by events of strong and cold wind blowing from Northeast (Bora) (Figure 2). Only one wind measurement station was available during the field campaigns, and since the largest distance achieved by the buoys from this station was about $2.5 \mathrm{~km}$, it was assumed that the wind field is spatial homogeneous in the study area. The wharf of the oil terminal is formed by a linear steel platform placed on a series of steel piles, having little influence on the wind spatial homogeneity. Only in presence of ships, as we will show later on in the paper, the wind by the downward side can be considered absent.

During the first 3 days, the wind intensity was in the range $2 \div 5 \mathrm{~m} / \mathrm{s}$. During the last 2 days of the field campaign, the wind blew from the first quadrant with a velocity of about $10 \mathrm{~m} / \mathrm{s}$.

The first buoy (labeled B6) was launched on September 12th, 2011, at 14:37. B6 was released near the stern of an oil tanker berthed at the eastern wharf, under Northwest wind conditions. After the release, the drifter initially moved parallel to the ship, and then it ran away following the wind direction (Figure 3). It was first directed towards the Southeast and then towards the Northeast and finally towards the Northwest landing on the shore after midnight. The wind is also plotted in Figure 3. It is first directed towards the Southeast and then the Northwest. The maximum wind intensity was $W_{\max }=4.64 \mathrm{~m} / \mathrm{s}$ while the maximum drifter velocity was $V_{\max }=0.29 \mathrm{~m} / \mathrm{s}$. The buoy reached the furthest eastern point of its trajectory 5 hours after the release. After that, its velocity dropped down to zero for 3.5 hours. Then the drifter started moving again and it reached the shore in 1.5 

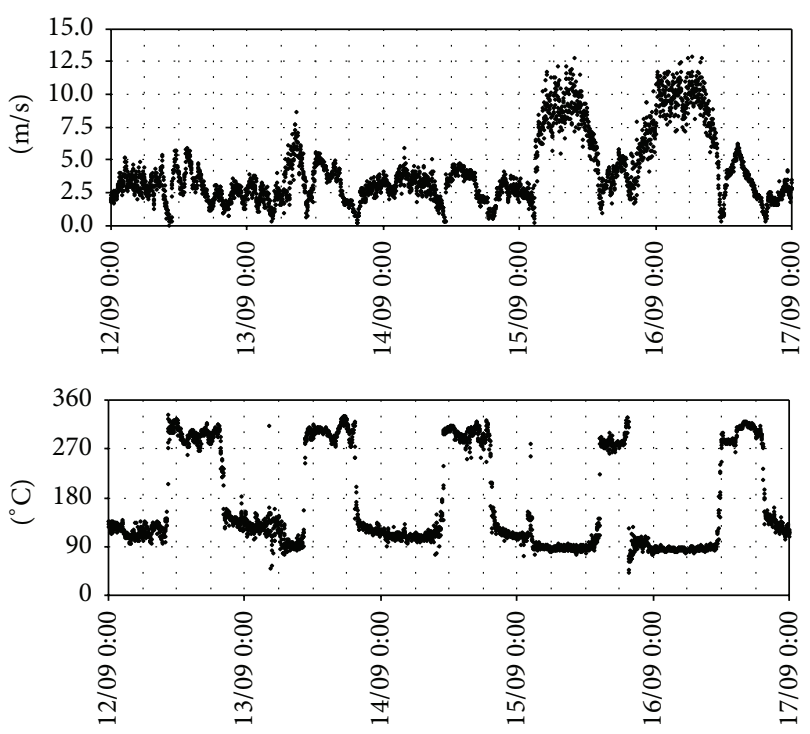

Figure 2: Wind intensity $(\mathrm{m} / \mathrm{s})$ and direction $\left(0^{\circ}\right.$ from North, $90^{\circ}$ from east) during the late-summer campaign considered in the present paper.

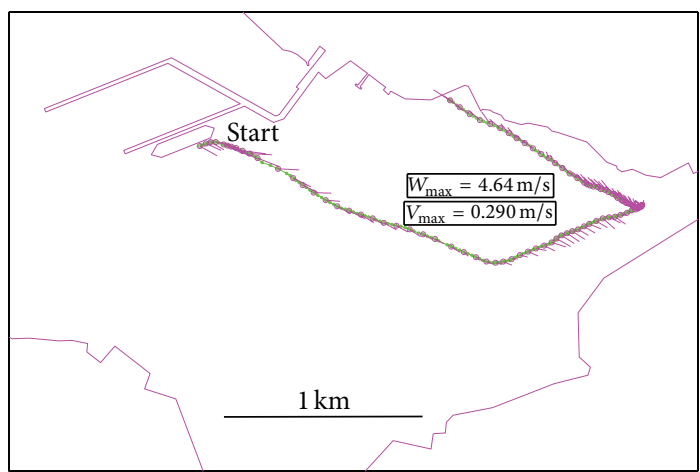

$-5 \mathrm{~m} / \mathrm{s}$

Figure 3: Drifter B6 released on September 12th, 2011, at 14:37, landed at shore at 24:40. The drifter positions are in green circles; the wind vectors are violet.

hours. The GPS coordinates of the trajectory are not filtered; the WAAS correction makes the position error negligible (Figure 3).

Comparison with velocity field obtained by means of high-resolution numerical simulations [10] clearly shows that the initial trajectory is related to the presence of a local circulatory motion developing down the ship. Overall, Figure 3 suggests that, in open area, where the free surface current is nearly aligned with the wind direction, the trajectory of the drifter is nearly aligned with the wind. On the other hand, downward of large structures or in the near-shore region, where the surface current has to deviate significantly from the wind direction, the drifter is essentially transported by the surface current.

Few minutes after the release of B6, another one (B12) was launched from a location close to the bow of the same

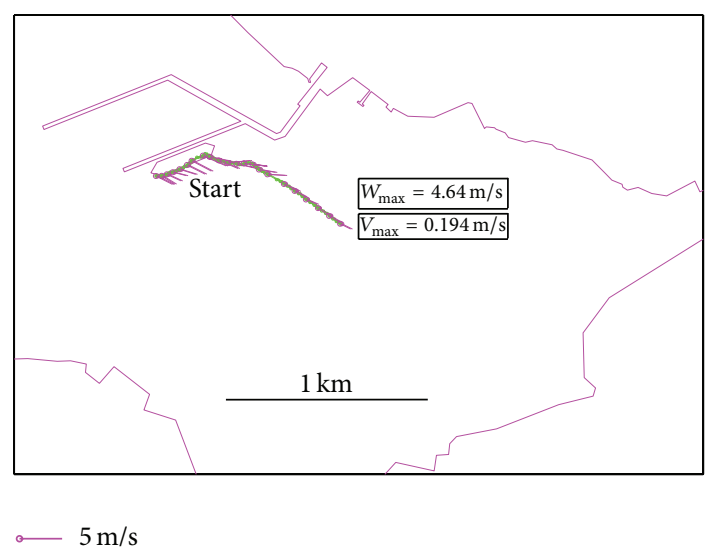

Figure 4: Drifter B12 released on September 12th, 2011, at 14:40, retrieval at 17:00.

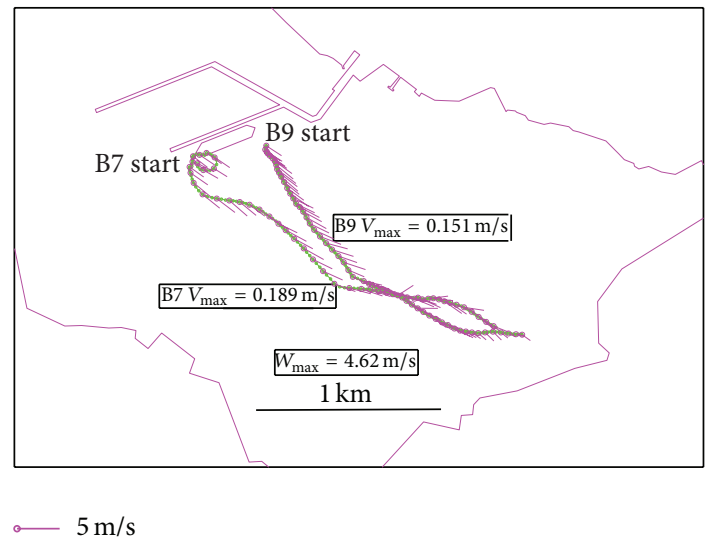

FIGURE 5: Drifter B7 released on September 14th, 2011, at 11:15, retrieval at 16:05. Drifter B9 released on September 14th, 2011, at 11:30, retrieval at 17:15.

oil tanker. Similarly to B6, the drifter first moved parallel to the ship, according to the local current direction, ruled by the small downward gyre, and then it turned Southeast (Figure 4). The maximum velocity was $V_{\max }=0.19 \mathrm{~m} / \mathrm{s}$, typical of sea currents, while $W_{\max }=4.64 \mathrm{~m} / \mathrm{s}$. B12 was taken out at 17:00 while travelling Southeast.

Buoys B7 and B9 were launched on September 14th, 2011, at 11:15 and 11:30. At that time, the wind was blowing from Northwest with maximum wind intensity $W_{\max }=4.62 \mathrm{~m} / \mathrm{s}$. The drifter B7 first described a counterclockwise vortex and then moved towards the Southeast $\left(V_{\max }=0.19 \mathrm{~m} / \mathrm{s}\right)$. It was finally taken out at 16:05 in the eastern part of the bay (Figure 5). The vortex is associated with the presence of a wake developing down the bow of an oil tanker berthed at the eastern wharf. Conversely, from its release B9 moved directly Southeast, showing the absence of circulatory motion in the region of the aft of the ship. The behavior of the two buoys suggests that, under Northwest wind conditions, the sea current is more intense toward the central part of the bay (bow region of the ship) due to the sheltering effect due to the coastline in the inshore region, where B9 was released. 


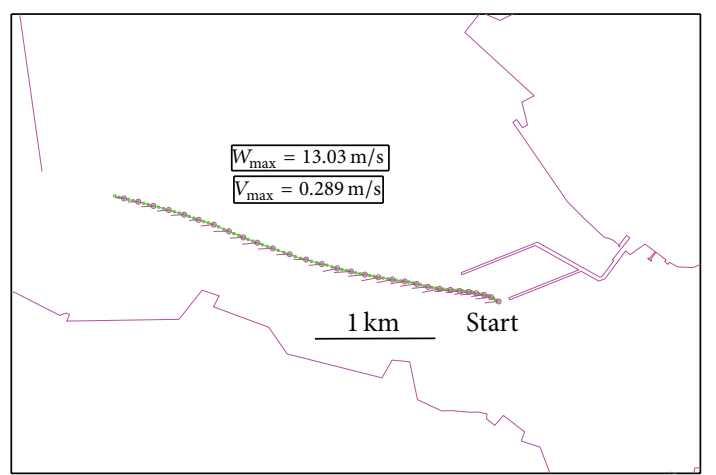

$-5 \mathrm{~m} / \mathrm{s}$

Figure 6: Drifter B6 released on September 15th, 2011, at 09:30, retrieval at 12:30.

From September 11th to 14th the wind was characterized by the typical breeze regime (diurnal from Northwest and nocturnal from the eastern quadrants) with low velocity. A wind with $W_{\max }=13.03 \mathrm{~m} / \mathrm{s}$ from east was present on September 15th, 2011. In the morning the buoy B6, released in the eastern wharf, rapidly moved $\left(V_{\max }=0.29 \mathrm{~m} / \mathrm{s}\right)$ west reaching the breakwaters of the harbor (Figure 6). The drifter traveled $2.5 \mathrm{~km}$ in 3 hours, with a mean velocity of $0.22 \mathrm{~m} / \mathrm{s}$, much larger than the mean values of previous days. Even in this case, the drifter trajectory did not exactly match the wind direction, confirming that the drifter trajectory is mainly influenced by the surface current.

Buoys B3 and B9 were launched on September 15th, 2011, at 14:10, when the wind was still blowing from east. Both buoys initially moved west (Figure 7). The wind turned and blew from the western quadrants at around 15:00. After that, the drifter B9 turned clockwise towards the Northeast and it was then stopped by artificial floating oil barriers placed under the wharfs and submerged by about $0.50 \mathrm{~m}$. In this case it was necessary to rescue the drifter stopped by the artificial obstacle. On the other hand, as the wind turned the drifter B3 turned counterclockwise moving to the Southeast.

Wind blew from east with an intensity of $W=8 \mathrm{~m} / \mathrm{s}$ when the buoys B9 and B6 were released on September 16th, 2011, at 10:10 and 10:25. At the beginning, both drifters were directed to the Southwest (Figure 8). The wind stopped blowing from east at around 11:00 and the typical diurnal breeze from west started. As the previous day it can be noticed that the drifters turned together with the wind, but their trajectories do not match the wind direction, confirming that the drifter trajectory is mostly dependent on the current direction with respect to the wind.

Maximum drifter velocity values and maximum wind intensities for each drifter release are shown in Table 1. Velocity values of $0.29 \mathrm{~m} / \mathrm{s}$ were recorded with wind intensities of both $13 \mathrm{~m} / \mathrm{s}$ and $5 \mathrm{~m} / \mathrm{s}$.

Finally, a question may be raised over the effect of Coriolis force on drifter trajectories. We cannot give a direct answer to the question, but we can give some argumentations based on dimensional analysis. The effect of Coriolis force is well known to be ruled by the Rossby number $R_{o}=V / L f$, where $V$

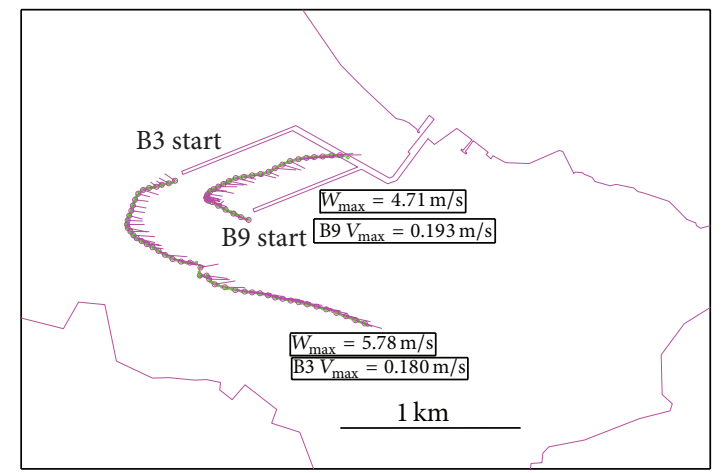

$-5 \mathrm{~m} / \mathrm{s}$

Figure 7: Drifter B3 released on September 15th, 2011, at 14:10, retrieval at 19:00. Drifter B9 released on September 15th, 2011, at 14:10, retrieval at 17:20.

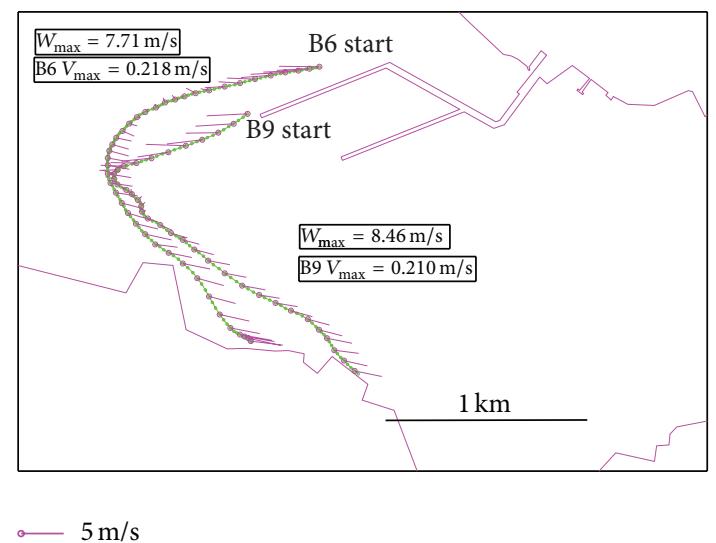

Figure 8: Drifter B9 released on September 16th, 2011, at 10:10, retrieval at 13:44. Drifter B6 released on September 16th, 2011, at $10: 25$, retrieval at 14:35.

is the velocity of the drifter, $L$ is a length scale of the problem, for instance, the distance travelled by the drifter, and $f$ is the Coriolis parameter of the order of $10^{-4}\left(\mathrm{~s}^{-1}\right)$ at the latitude of the Muggia bay. In the Northern Hemisphere the Coriolis force is known to deviate the trajectory by the right side. The Coriolis force is more active when the velocity is small, so, considering the smallest velocity recorded by our drifters we have an estimation of $R_{o} \sim 1$ when the drifter travels by few $(1 \div 2)$ kilometers. In these situations, the effect of Coriolis force is very weak but still detectable.

\section{Conclusions}

In the present paper we present a new small drifter prototype, suited for shallow water conditions and able to trace the trajectory of the surface current, within the first $0.20 \mathrm{~m}$ below the free surface. The drifter was used to detect the trajectory of the surface current in the Muggia bay, the industrial harbor of the city of Trieste (Italy). They were released under different meteorological conditions, with wind direction and intensity varying in a wide range of values. As a general comment, we 
TABLE 1: Maximum drifter velocity values and maximum wind intensities.

\begin{tabular}{|c|c|c|c|c|c|}
\hline Buoy & Release & Retrieval & $V_{\max }(\mathrm{m} / \mathrm{s})$ & $W_{\text {mean }}(\mathrm{m} / \mathrm{s})$ & $W_{\max }(\mathrm{m} / \mathrm{s})$ \\
\hline B6 & 12.09.2011 14:37 & 12.09.2011 24:40 & 0.29 & 2.39 & 4.64 \\
\hline B12 & 12.09 .2011 14:40 & 12.09.2011 17:00 & 0.19 & 3.14 & 4.64 \\
\hline B7 & 14.09.2011 11:15 & 14.09.2011 16:05 & 0.19 & 3.95 & 4.62 \\
\hline B9 & 14.09.2011 11:30 & 14.09.2011 17:15 & 0.15 & 3.63 & 4.62 \\
\hline B6 & 15.09.2011 09:30 & 15.09.2011 12:30 & 0.29 & 8.52 & 13.03 \\
\hline B3 & 15.09.2011 14:10 & 15.09.2011 19:00 & 0.18 & 3.72 & 5.78 \\
\hline B9 & 15.09.2011 14:10 & 15.09.2011 17:20 & 0.19 & 3.26 & 4.71 \\
\hline B6 & 16.09.2011 10:25 & 16.09 .2011 14:35 & 0.22 & 3.81 & 7.71 \\
\hline B9 & 16.09.2011 10:10 & 16.09.2011 13:44 & 0.21 & 3.62 & 8.46 \\
\hline
\end{tabular}

can say that since the drifter is only marginally exposed to the action of the wind, their motion is more likely driven by the surface current in the sea. Overall the trajectory of the drifters suggests that under the typical conditions of wind blowing from the western quadrants, the surface currents are driven east and then it turns due to the presence of the coastline. Under eastern wind conditions the surface currents develop primarily from east to west driving the surface internal water out of the bay.

Finally, dimensional considerations suggest that the Coriolis force may have a weak effect on the trajectory of the surface current within the bay.

\section{Conflict of Interests}

The authors declare that there is no conflict of interests regarding the publication of this paper.

\section{Acknowledgments}

Vincenzo Armenio has been supported by the University of Trieste under project FRA 2013 Modellistica Numerica e Sperimentale di Fenomeni di Erosione Localizzata in Alvei Fluviali and by the Flag project RITMARE, Action SP5-WP4AZ3-UO06.

\section{References}

[1] S. E. Pazan, "Intercomparison of drogued and undrogued drift buoys," in Proceedings of OCEANS '96. MTS/IEEE. Prospects for the 21st Century, vol. 2, Fort Lauderdale, Fla, USA, September 1996.

[2] P. P. Niiler and J. D. Paduan, "Wind-driven motions in the northeast pacific as measured by lagrangian drifters," Journal of Physical Oceanography, vol. 25, no. 11, pp. 2819-2830, 1995.

[3] R. Lumpkin and M. Pazos, "Measuring surface currents with SVP drifters: the instrument, its data and some results," in Lagrangian Analysis and Prediction of Coastal and Ocean Dynamics, A. Griffa, A. D. Kirwan Jr., A. J. Mariano, T. Özgökmen, and H. T. Rossby, Eds., pp. 39-67, Cambridge University Press, Cambridge, UK, 2007.

[4] R. E. Davis, "Drifter observations of coastal surface currents during CODE: the method and descriptive view," Journal of Geophysical Research, vol. 90, no. 3, pp. 4741-4755, 1985.
[5] J. P. Manning, D. J. McGillicuddy Jr., N. R. Pettigrew, J. H. Churchill, and L. S. Incze, "Drifter observations of the gulf of maine coastal current," Continental Shelf Research, vol. 29, no. 7, pp. 835-845, 2009.

[6] P.-M. Poulain, A. Bussani, R. Gerin et al., "Mediterranean surface currents measured with drifters: from basin to subinertial scales," Oceanography, vol. 26, no. 1, pp. 38-47, 2013.

[7] D. Johnson, R. Stocker, R. Head, J. Imberger, and C. Pattiaratchi, "A compact, low-cost GPS drifter for use in the oceanic nearshore zone, lakes, and estuaries," Journal of Atmospheric and Oceanic Technology, vol. 20, no. 12, pp. 1880-1884, 2003.

[8] T. Kõuts, S. Verjovkina, P. Lagemaa, and U. Raudsepp, "Use of lightweight on-line GPS drifters for surface current and ice drift observations," in Proceedings of the IEEE/OES US/EU Baltic International Symposium, Riga, Latvia, August 2010.

[9] J. MacMahan, J. Brown, and E. Thornton, "Low-Cost handheld global positioning system for measuring surf-zone currents," Journal of Coastal Research, vol. 25, no. 3, pp. 744-754, 2009.

[10] A. Petronio, F. Roman, C. Nasello, and V. Armenio, "Large eddy simulation model for wind-driven sea circulation in coastal areas," Nonlinear Processes in Geophysics, vol. 20, no. 6, pp. 10951112, 2013. 


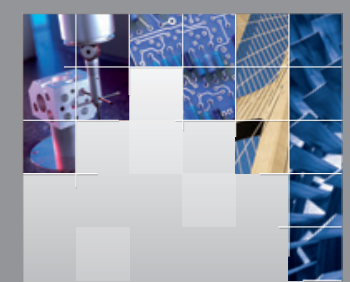

\section{Enfincering}
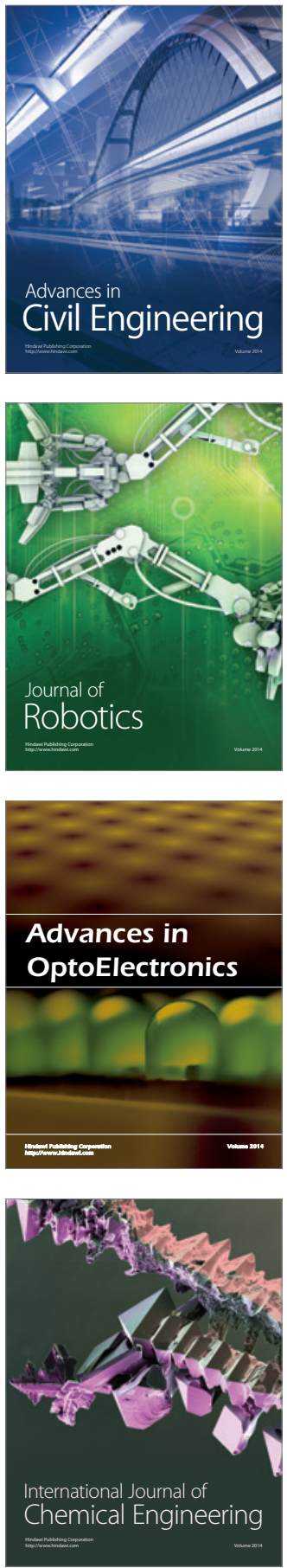

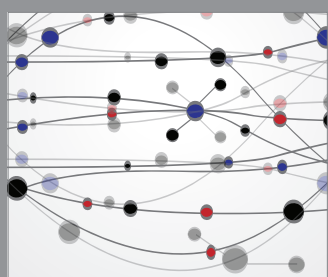

The Scientific World Journal

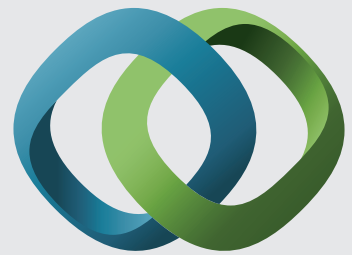

\section{Hindawi}

Submit your manuscripts at

http://www.hindawi.com
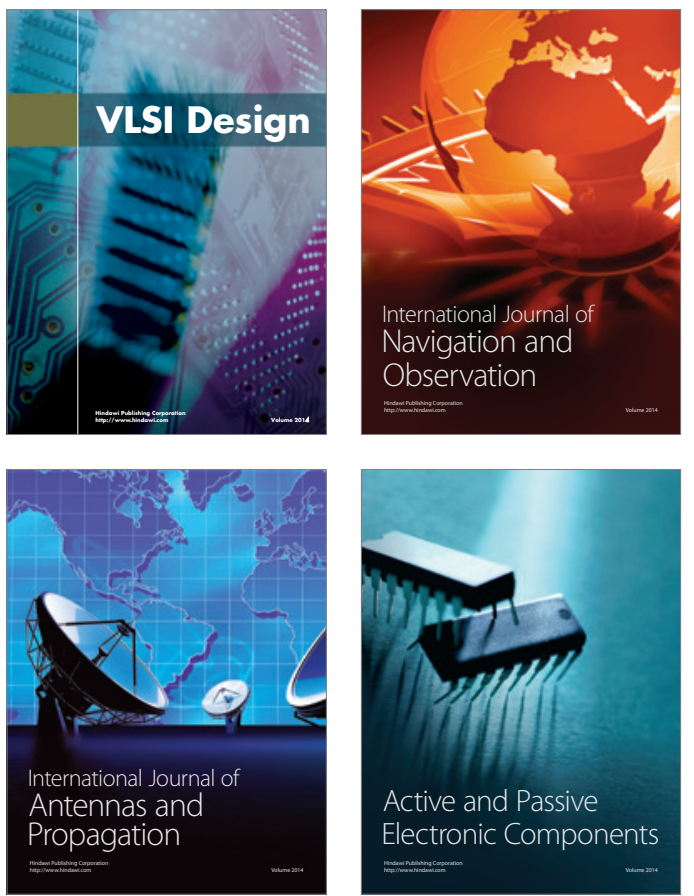
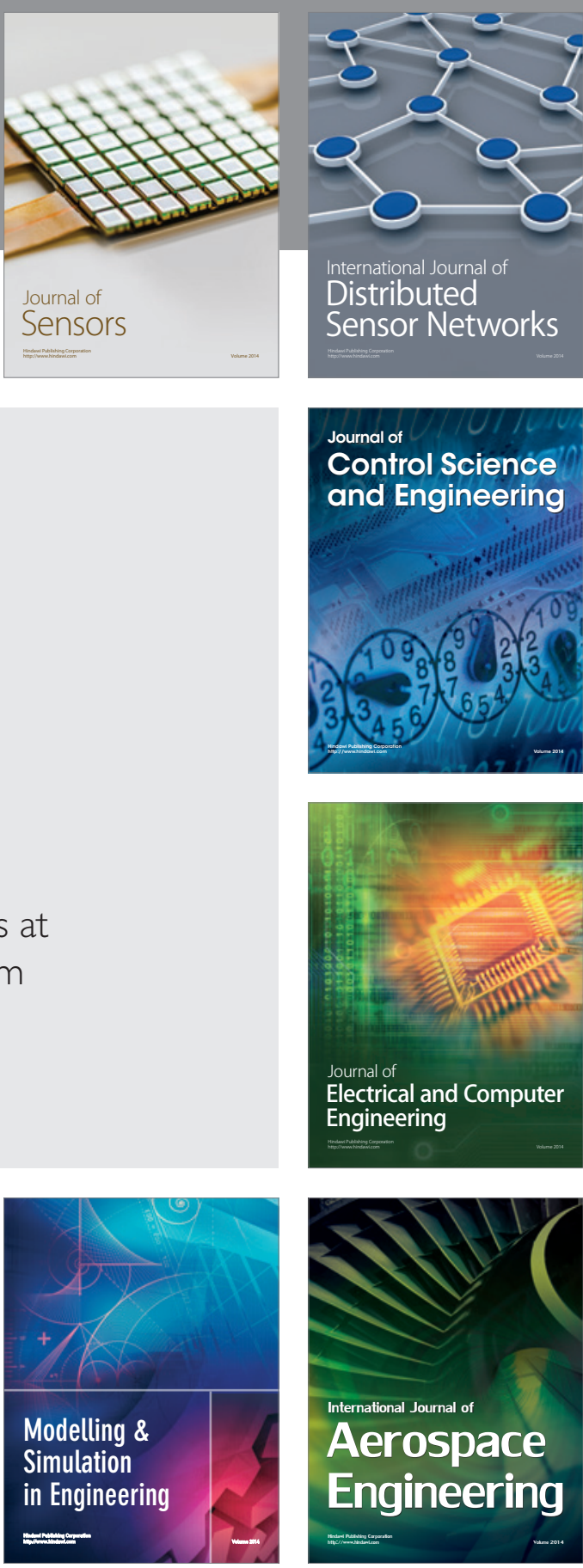

International Journal of

Distributed

Sensor Networks

Journal of

Control Science

and Engineering
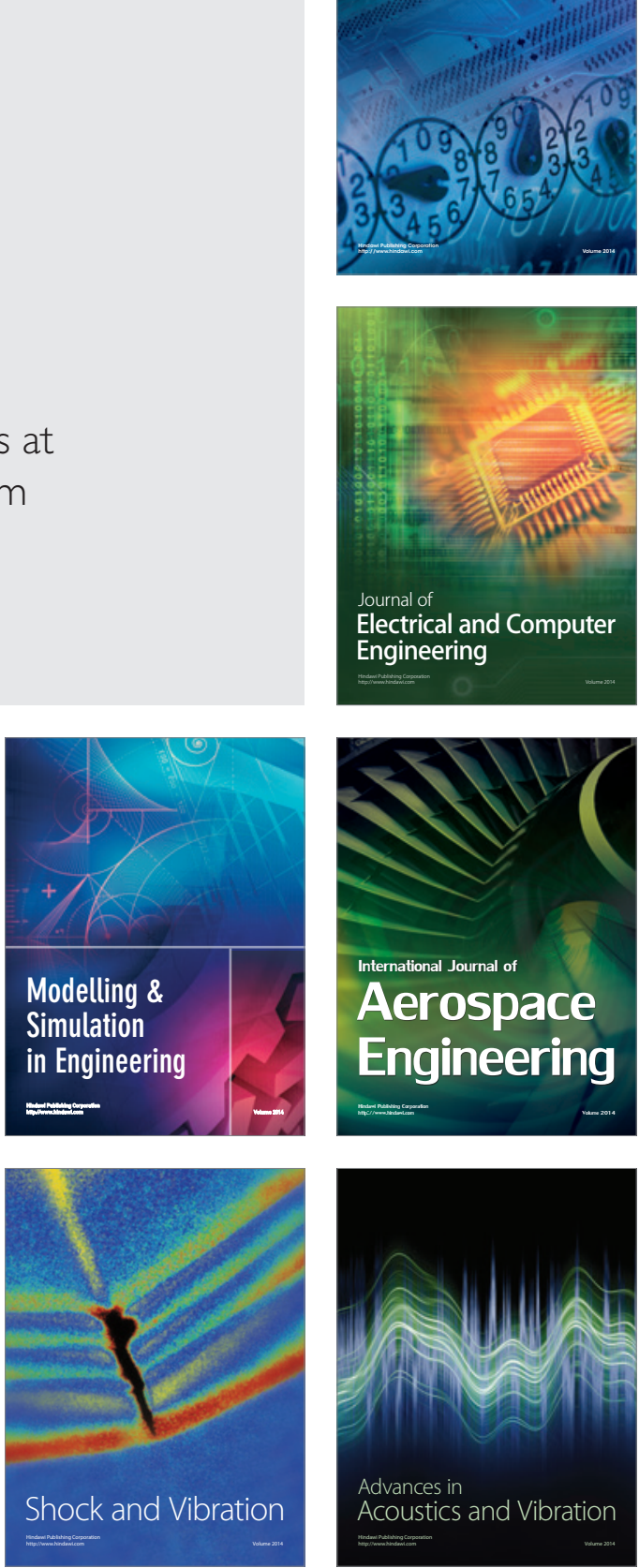